\title{
Trends and Variability in Precipitable Water Vapor throughout North China from 1979 to 2015
}

\author{
Wang Peng, ${ }^{1}$ Xie Tongchuan, ${ }^{1}$ Dai Jiageng, ${ }^{1}$ Sun Jingmin,, ${ }^{1}$ Wu Yanling, ${ }^{1}$ Song Qingli, ${ }^{1}$ \\ Dai Xin, ${ }^{1}$ Yuan Hongliang, ${ }^{2}$ Song Dejun, ${ }^{2}$ and Zhao Jinrong ${ }^{1}$ \\ ${ }^{1}$ Longfengshan Atmospheric Background Regional Station, Heilongjiang Meteorological Administration, Wuchang 150209, China \\ ${ }^{2}$ Heilongjiang Meteorological Administration, Harbin 157399, China
}

Correspondence should be addressed to Wang Peng; wangpeng7123729@163.com and Song Qingli; Songqingli@yeah.net

Received 6 August 2017; Revised 2 November 2017; Accepted 13 November 2017; Published 21 December 2017

Academic Editor: Stefania Bonafoni

Copyright (C) 2017 Wang Peng et al. This is an open access article distributed under the Creative Commons Attribution License, which permits unrestricted use, distribution, and reproduction in any medium, provided the original work is properly cited.

\begin{abstract}
This study analyzed the variability and trends in precipitable water vapor (PWV) in North China from 1979 to 2015 . The spatial distribution of annual mean PWV was generally characterized by two high PWV centers in Eastern China and the Tarim Basin and two low PWV centers in Northern Tibet and Qinghai Province and in Inner Mongolia. The levels of seasonal mean PWV were highest in summer, followed by autumn and spring, and lowest in winter. The maximum monthly mean PWV occurred in July and August, while the minimum occurred in December to February. Increasing trends in PWV, with the trend magnitude ranging from 0.1 to $1.2 \mathrm{~mm}_{\text {decade }}{ }^{-1}$ over North China, were observed in the radiosonde, ERA-interim, and MERRA-2 PWV data from 1979 to 1999; but a slightly decreasing trend of $-0.4 \mathrm{~mm} \mathrm{decade}^{-1}$ from radiosonde was found in most regions of North China from 1979 to 2007. A monotonically increasing PWV trend was detected throughout North China between 1979 and 1999 , with the maximum trend occurring in summer and the minimum occurring in winter. For the period of 1979-2007, a slightly but less marked decreasing trend was found at most stations in North China in all four seasons.
\end{abstract}

\section{Introduction}

Water vapor plays a crucial role in climate change, hydrological processes, Earth's energy balance, and weather systems [1-3]. Water vapor is also the most abundant greenhouse gas in the atmosphere, and it accounts for about $60 \%$ of the natural greenhouse effect [4]. Because of this, the saturation vapor pressure is expected to increase as a response to rises in air temperature. Thus, atmospheric water vapor provides a strong positive feedback for global warming as well as carbon dioxide, ozone, methane, and other greenhouse gases $[1,5-9]$. Therefore, how water vapor changes in both the real atmosphere and climate models is significant, not only for a better understanding of water vapor feedback on global warming but also for the exploration of climate change.

Over the past few years, various studies have been performed to detect the changes in precipitable water vapor (PWV) using a variety of PWV datasets, which can be retrieved from various sensors such as Global Positioning System (GPS) receivers [10], radiosondes [6, 11], microwave radiometers [12, 13], Raman radar [14], multifilter rotating shadow band radiometers (MFRSR) [15], satellite remote sensing $[16,17]$, and ground-based sun photometry $[18,19]$. Traditionally, the long-term PWV observation records from radiosondes represent an important resource for monitoring the variation of atmospheric water vapor. As it boasts high accuracy and high vertical resolution, radiosonde PWV is also often used as the reference data in evaluating the performance of other PWV detection techniques [20-22]. However, it is difficult to quantify an accurate PWV trend from radiosonde PWV due to limitations such as incomplete and inhomogeneous observations and sparse spatial distributions $[6,23]$. Moreover, several factors such as changes in instrumentation, uncontrollable balloons, upgrades to instruments, and temporal inhomogeneities often cause spurious shifts in the radiosonde PWV time series [24]. This means that the long-term trend of PWV derived from radiosonde detection may be influenced by decisions of the researchers, including quality control procedures, site screening processes, and bias correction [23]. 
Atmospheric reanalysis datasets are produced by assimilating various types of observations (including ground and satellite observations) into a dynamically coherent dataset, based on an atmospheric general circulation model [4, 9, 25]. Reanalysis data have been used widely in atmospheric research topics, such as climate change, because they have advantages such as multivariable outputs, global coverage, homogeneous records, and spatial integrity [26, 27]. It is worth noting that reanalysis data may not be so reliable for some areas with limited or absent observational data for use in the data assimilation $[28,29]$. Moreover, the expected error in ground and satellite observations that are assimilated into a reanalysis system may propagate large biases in reanalysis products. These errors may induce spurious long-term changes in reanalysis water vapor.

Many previous studies have revealed the PWV trends on different regional scales and over different time periods using a variety of PWV datasets. It has been shown that there has been an upward trend in PWV at most sites in the Northern Hemisphere, using radiosonde observations made during 1973-1995 [30]. Based on 27 years of radiosonde observations, a significant upward trend in PWV has been observed in the northern part of China, but a downward trend has been seen in Southern China for the period of 1979-2005 [31]. For the period of 1979-2001, the magnitude of the global PWV increase was found to be $0.26 \mathrm{~mm}$ decade $^{-1}$, using the ERA40 reanalysis of the European Centre for Medium-Range Weather Forecasts (ECMWF) [32]. By using a variety of PWV datasets, including the ECMWF and National Centers for Environmental Prediction reanalyses, GPS, radiosonde, and microwave satellite observations, the variability and trend in global PWV between 1979 and 2014 have been analyzed [Chen et al., 2016]. The study showed positive global PWV trends for all five PWV datasets during three different periods: 1979-2014, 1992-2014, and 2000-2014.

China, especially North China, is a typical region for studying water vapor feedback on global warming [33]. In order to strengthen understanding of climate change, it is necessary to analyze the PWV distribution and variations throughout North China in recent decades [34]. In this paper, the spatial and temporal variations of annual, seasonal, and monthly PWV distributions throughout North China are examined using the latest 37-year ERA-interim reanalysis from ECMWF. Meanwhile, the PWV datasets from 45 radiosonde stations in North China are used to analyze the annual and seasonal trends during three different periods (1979-1999, 1979-2007, and 2008-2015) associated with the latest humidity sensors changes that have been taking place in China since about 2007 [35, 36]. In addition, the latest ERA-interim reanalysis products from ECMWF and the second Modern-Era Retrospective Analysis for Research and Applications (MERRA-2) between 1979 and 2015 are also exploited to derive PWV trends for a direct comparison with radiosonde data.

\section{Data and Method}

2.1. Radiosonde Station Description and PWV Retrieval. Based on a balloon-borne platform, radiosondes can provide in situ measurements of meteorological parameters including temperature, pressure, relative humidity, and wind speed and direction at different heights. Radiosonde balloons are generally launched twice daily, at 00:00 and 12:00 UTC (local time $+8 \mathrm{~h}$ ). The measurement precisions of the temperature, pressure, and relative humidity are $0.2-0.3^{\circ} \mathrm{C}, 1-2 \mathrm{hPa}$, and 4 $5 \%$, respectively. PWV can be calculated from an integral of the meteorological profiles measured by a radiosonde. It has been reported that the uncertainty in radiosonde $\mathrm{PWV}$ data is from 5 to $8 \%[37,38]$. The total columnar water vapor can be calculated using the following equation [39]:

$$
\mathrm{PWV}=\frac{1}{g} \int_{p_{1}}^{p_{2}} \frac{0.622 e}{p-e} d p
$$

where $g$ is the acceleration due to gravity; $p_{1}$ and $p_{2}$ are atmospheric pressure at the lower and upper layers, respectively (unit: Pascal); and $e$ is the vapor pressure (unit: Pascal).

The PWV is calculated from integration of water vapor mass through all levels of the sounding in this paper. Only the Chinese radiosonde data from 1979 to 2015 were selected to retrieve PWV. The PWV data quality has been controlled according to the previously reported procedures [31, 40]: (1) Data from stations are excluded when obvious breaks are found. (2) Data from stations without two complete daily observations at 00:00 and 12:00 UTC are rejected. (3) In the analysis of annual mean PWV time series for each station, at least 15 observation days from a month are used to obtain a monthly mean value, and at least eight valid months from a year are needed to derive the annual and seasonal mean values. As a result, a total of 45 radiosonde stations in North China were selected for this study for the period of 1979-2015. Data from the 45 radiosonde stations are available from the website of the Department of Atmospheric Science of the University of Wyoming (http://weather.uwyo.edu/upperair/sounding.html). Figure 1 shows the geographical positions of the 45 radiosonde stations in North China. It can be seen that they are situated at longitudes ranging from $75^{\circ} \mathrm{E}$ to $130^{\circ} \mathrm{E}$, at latitudes ranging from $32^{\circ} \mathrm{N}$ to $52^{\circ} \mathrm{N}$, and at elevations ranging from $400 \mathrm{~m}$ a.s.l. to $4800 \mathrm{~m}$ a.s.l. (see Figure 1).

2.2. ERA-Interim Reanalysis PWV Data. ERA-interim is the latest global atmospheric reanalysis produced by the ECMWF. It covers the data-rich period from 1 January 1979 and is continuously updated in real time [23]. These data can be downloaded from the ECMWF Public Datasets web interface (https://www.ecmwf.int/). ERA-interim improved the quality of the reanalysis products compared with ERA40 [23]. The data assimilation system uses a four-dimensional variational analysis system that is based on a 2006 release of the IFS (Cy31r2). The PWV data derived from the ERA-interim reanalysis are based on various water vapor observations, including clear-sky radiance measurements from polar-orbiting and geostationary sounders, as well as the images of remote sensing satellites such as the Total Ozone Mapping Spectrophotometer [41], Special Sensor Microwave Imager (SSM/I) [42], TIROS Operational Vertical Sounder (TOVS) [43], and High Resolution Infrared Radiation Sounder $[44,45]$. 


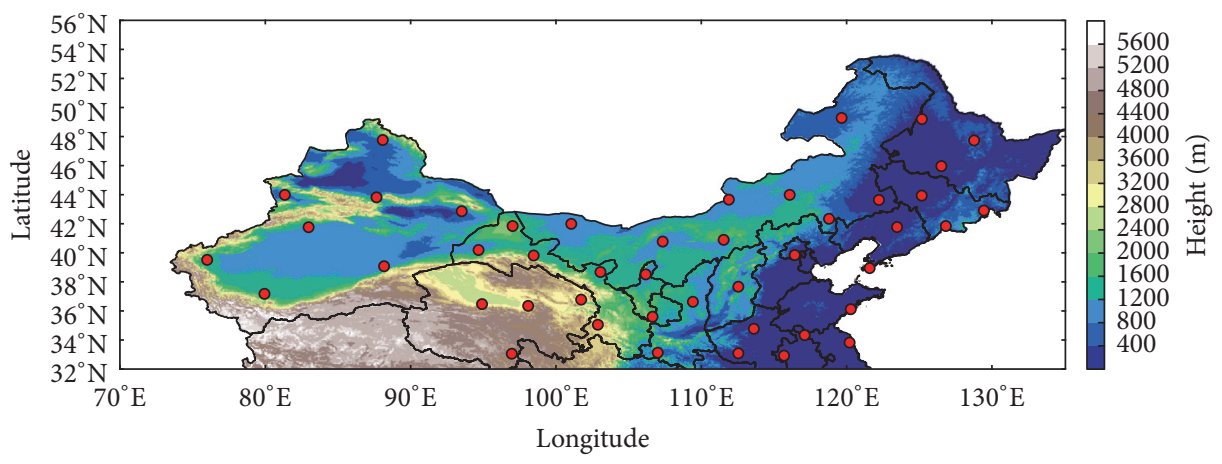

- Radiosonde sites

FIgURE 1: Geographical distribution of the 45 radiosonde stations selected for this study.

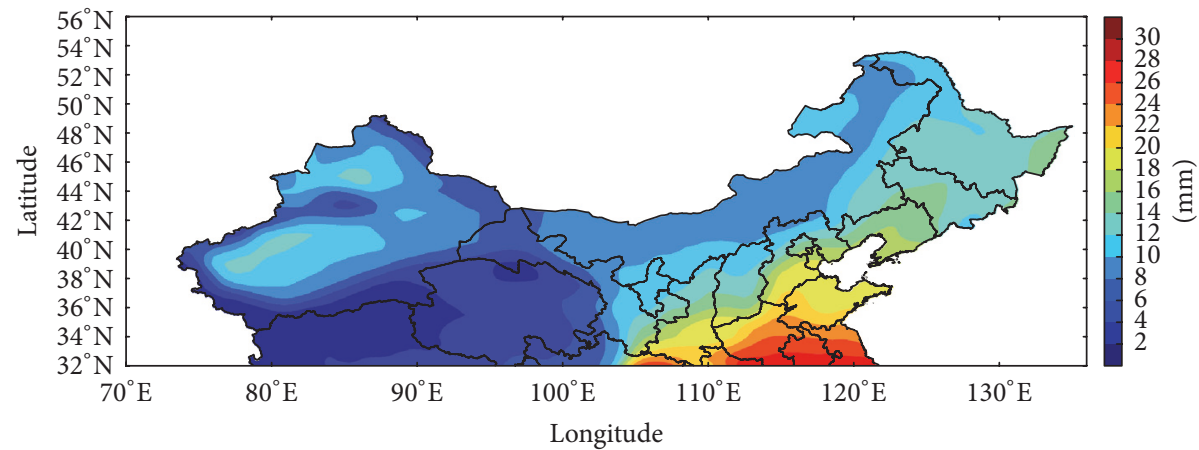

Figure 2: Annual mean ERA-interim PWV throughout North China from 1979 to 2015.

In this study, the monthly mean PWV data derived from the ERA-interim reanalysis from 1979 to 2015 were used. The spatial resolution of the ERA-interim reanalysis PWV products used in this study was $0.5^{\circ} \times 0.5^{\circ}$ in latitude and longitude. The monthly mean PWV data were calculated by averaging daily PWV data, which had a $6 \mathrm{~h}$ temporal resolution, and then the annual mean PWV data were obtained by averaging the monthly PWV data. Additionally, the seasonal means were obtained for spring (March, April, and May), summer (June, July, and August), autumn (September, October, and November), and winter (December, January, and February) by averaging the monthly means in each season.

2.3. MERRA-2 Reanalysis PWV Data. The second ModernEra Retrospective Analysis for Research and Applications (MERRA-2) is a NASA atmospheric data reanalysis for the satellite era. It replaces the original MERRA reanalysis data [46] using a three-dimensional upgraded version of the Goddard Earth Observing System Data Assimilation System (Version 5.12.4). Unlike in MERRA, all data collections from MERRA-2 are provided at the same resolution of $0.5^{\circ} \times$ $0.625^{\circ}$ in latitude and longitude. The PWV data derived from the MERRA-2 reanalysis are based on various water vapor observations, including the newer microwave sounders and hyperspectral infrared radiance instruments such as the Atmospheric Infrared Sounder [47], SSM/I, and TOVS.
In this study, the monthly mean PWV data derived from the MERRA-2 reanalysis between 1979 and 2015 were used. The methods used to calculate the annual mean PWV and seasonal mean PWV were consistent with the ERA-interim PWV, as mentioned above.

Based on the annual or seasonal mean PWV data from radiosondes, the ERA-interim reanalysis, and the MERRA2 reanalysis, the annual or seasonal linear trend in PWV was estimated by using the least-squares linear regression method. This method is designed to determine the equation of best fit to time series data by minimizing the sum of the squares of the errors in the residuals.

\section{Results and Discussion}

\subsection{Spatial Distribution and Variability of $P W V$ throughout North China}

3.1.1. Annual Mean PWV Levels throughout North China. A previous study [48] confirmed that the performance of ERA-interim PWV data is better than that of MERRA-2 in North China (see also a larger correlation coefficient between radiosonde and ERA-interim in Figure 5). Thus, the ERAinterim PWV data were used to study the spatial distribution of PWV throughout North China in this study. Figure 2 presents the spatial distribution of annual mean PWV 


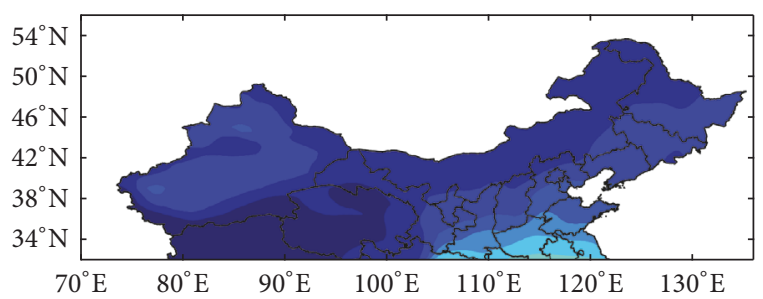

(a) Spring

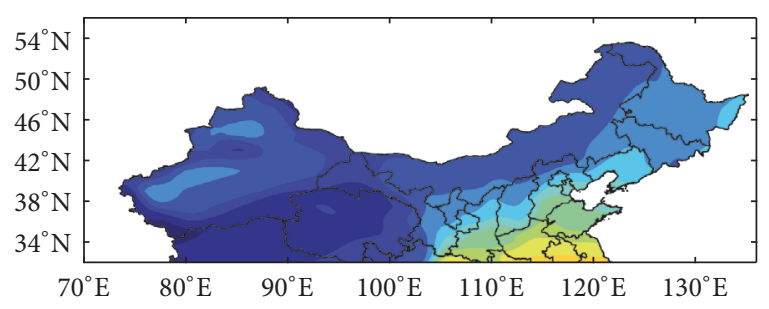

(c) Autumn

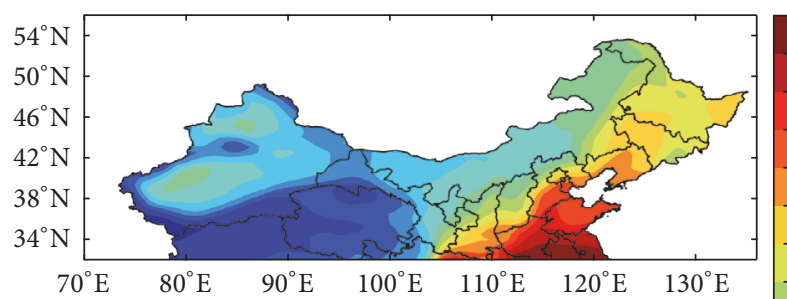

(b) Summer

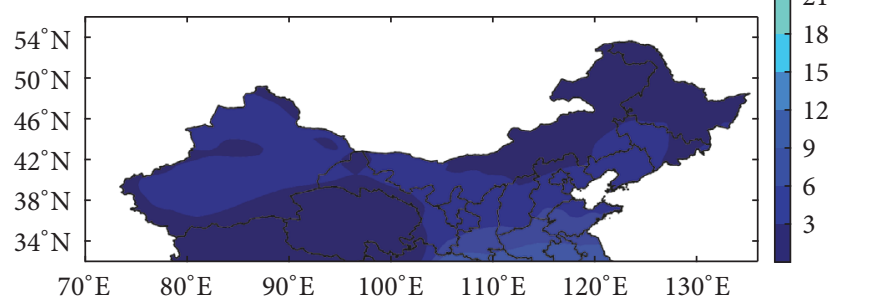

(d) Winter

FIGURE 3: Seasonal mean ERA-interim PWV throughout North China in (a) spring, (b) summer, (c) autumn, and (d) winter from 1979 to 2015.

throughout North China, derived from the 37-year ERAinterim reanalysis data. The distribution of PWV throughout North China showed clear geographical differences. This spatial pattern of annual mean PWV was generally characterized by two high and two low PWV centers over North China (Figure 2). Two high PWV centers were in Eastern China, with PWV from 20 to $28 \mathrm{~mm}$, and in the Tarim Basin of Northwestern China, with PWV of about $12 \mathrm{~mm}$. The high PWV level in Xinjiang Province may have been related to the water vapor transport from the Mediterranean and Caspian seas [49]. Two low PWV centers were in the areas with high-altitude regions around Northern Tibet and Qinghai Province, with PWV from 2 to $8 \mathrm{~mm}$, and in the high-latitude Inner Mongolia region, with PWV of about $8 \mathrm{~mm}$.

\subsubsection{Seasonal and Monthly Variations throughout North} China. Figure 3 shows the distribution of the 37-year averaged PWV for spring, summer, autumn, and winter. The spatial distribution of PWV throughout North China was characterized by two high PWV centers and two PWV low centers, which remained unchanged over all four seasons, although the intensity of the PWV centers varied between spring, summer, autumn, and winter. Overall, the levels of seasonal mean PWV were highest in summer, followed by autumn and spring, and were lowest in winter. In spring, except in Eastern China, the PWV throughout North China remained at a low level. Affected by the East Asian monsoon, the PWV increased markedly in the summer in most parts of North China. The PWV in the Eastern China area finally reached a maximum value of about $45 \mathrm{~mm}$. The PWV in Xinjiang Province reached the same level as in Inner Mongolia, with a value of about $18 \mathrm{~mm}$. In autumn, with the weakening of the monsoon, the PWV in Xinjiang Province, Eastern China, Northeast China, and Inner Mongolia decreased significantly. In winter, the PWV levels were low, with a value of lower than $9 \mathrm{~mm}$ for most parts of North China.
Monthly mean PWVs were retrieved from 37 years of monthly PWV data, and the monthly mean distribution of PWV from January to December throughout North China is shown in Figure 4. The monthly mean PWV distribution throughout North China showed obvious monthly differences. The highest PWV level in North China occurred in July and August, with a PWV value of greater than $45 \mathrm{~mm}$ in Eastern China, greater than $18 \mathrm{~mm}$ in Xinjiang Province and Inner Mongolia, and greater than $9 \mathrm{~mm}$ in Northern Tibet and Qinghai Province, which was closely related to the enhanced intensity of the East Asian summer monsoon and increased evaporation resulting from increased temperature during this period. The lowest PWV level in North China occurred in December, January, and February, with a PWV value of less than $9 \mathrm{~mm}$.

3.1.3. Interannual Variation throughout North China. Averaged time series of annual mean PWV for all radiosonde stations, ERA-interim, and MERRA-2 throughout North China are plotted in Figure 5. All North China values are based on an arithmetic average of the 45 individual radiosonde sites and a regional average of all grid points from ERAinterim and MERRA-2 PWV data. As shown in Figure 5, the trends in annual mean PWV interannual variations in the ERA-interim $(r=0.619)$ and MERRA-2 $(r=$ $0.589)$ reanalyses were highly consistent with the observed radiosonde PWV series throughout North China. For longterm PWV variations, however, there were clear differences between ERA-interim/MERRA-2 PWV reanalysis data and radiosonde PWV observations, especially before 2003, which resulted from wet biases in the reanalyses in the earlier period [48]. In addition, as shown in Figure 5, there was a stable bias of about $0.25 \mathrm{~mm}$ between the annual mean PWV time series from ERA-interim and MERRA-2 before 2000. From 2001 to 2005, the ERA-interim annual mean PWV time series agreed well with that of MERRA-2. After 2005, a stable bias continued to exist. 


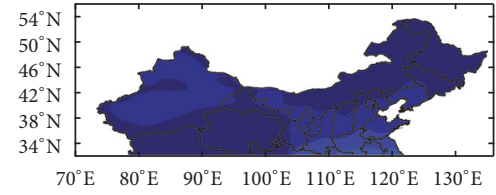

(a) January

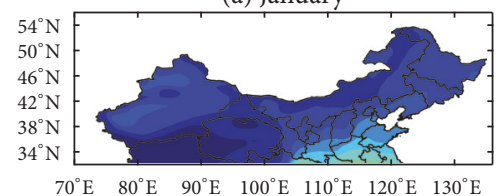

(d) April

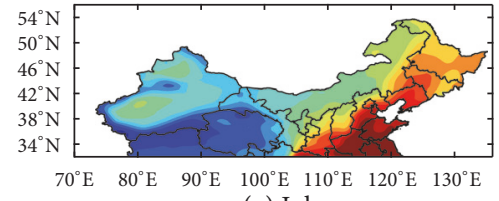

(g) July

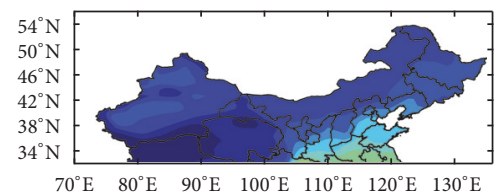

(j) October

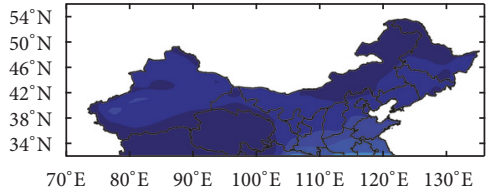

(b) February

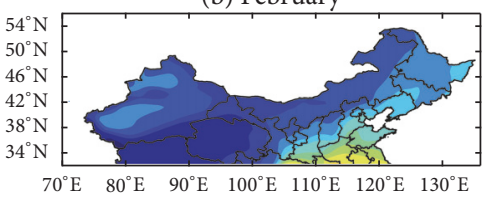

(e) May

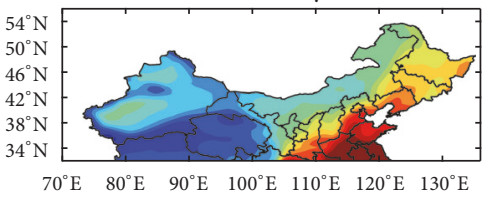

(h) August

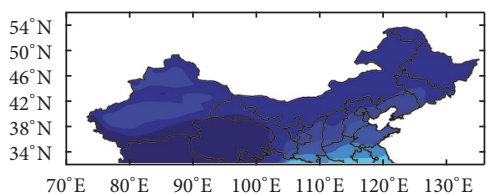

(k) November

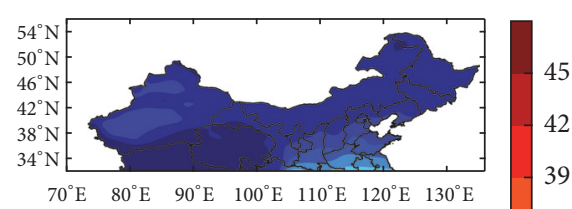

(c) March

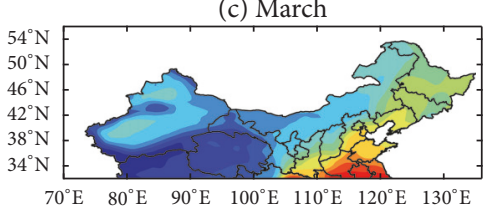

(f) June

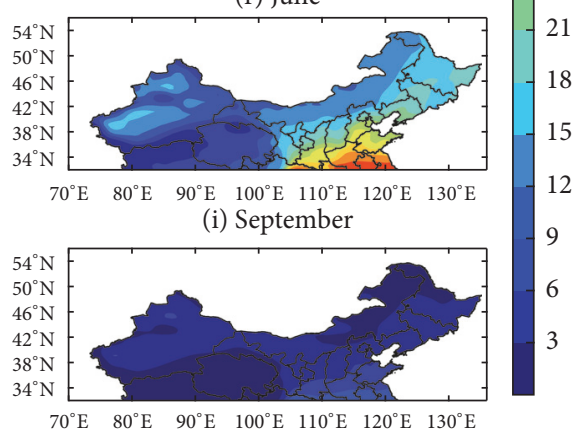

(1) December

FIgURE 4: Monthly mean ERA-interim PWV throughout North China in (a-c) January, February, and March; (d-f) April, May, and June; (g-i) July, August, and September; and (j-l) October, November, and December from 1979 to 2015.

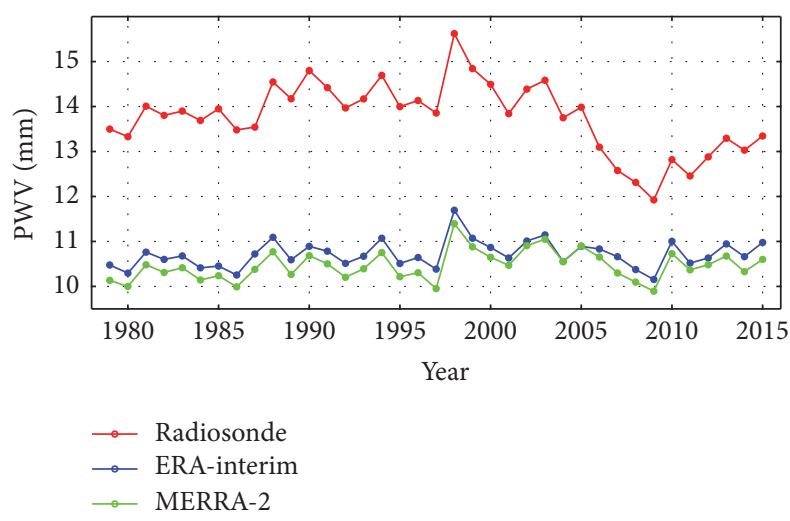

Figure 5: Annual averaged PWV time series, derived from radiosonde, ERA-interim, and MERRA-2 data, throughout North China during the period of 1979-2015.

Based on Figure 5, it is interesting to note that there was an obvious increase during 1979-1998, with the largest PWV value occurring in 1998. A corresponding significant decrease was observed during 1999-2009, with the lowest PWV value occurring in 2009. The abrupt PWV increases observed during 1997-1998 and 2009-2010 were likely related to El Niño events [Chen et al., 2016].

In order to investigate the variation and trend in PWV in major cities in North China, nine provincial capital radiosonde stations (Urumchi, Xining, Yinchuan, Beijing, Taiyuan, Hohhot, Changchun, Harbin, and Zhengzhou) were used. These radiosonde stations were chosen to represent the different characteristics of PWV in typical regions throughout North China. The interannual variation in PWV at various stations is presented in Figure 6. Significant decreasing trends were observed at Harbin, Yinchuan, and Beijing from 1998 to 2006. The annual mean PWV decreased from $16.2 \mathrm{~mm}$ to $11.7 \mathrm{~mm}$ at Harbin, from $14.4 \mathrm{~mm}$ to $10.9 \mathrm{~mm}$ at Yinchuan, and from $20.9 \mathrm{~mm}$ to $16.9 \mathrm{~mm}$ at Beijing during 1998-2006. For the stations in central China, a significant increasing trend of PWV was observed at Zhengzhou during two periods (1979-1990 and 1997-1998), with the peak value occurring in 1998 at $25.6 \mathrm{~mm}$ (Figure 6(c)). Meanwhile, a clear decreasing trend in PWV was observed during two periods (1990-1997 and 1998-2008), with the lowest value occurring in 1997 at $19.6 \mathrm{~mm}$.

For the stations in Northwest China, a clear increasing trend in PWV was observed at Urumchi, Xining, and Yinchuan from 1979 to 2002, followed by a decrease during 2003-2009 at Urumchi and Xining (Figure 6(a)). The largest PWV occurred in 1999, with a value of $12.6 \mathrm{~mm}, 11.6 \mathrm{~mm}$, and $14.4 \mathrm{~mm}$ for Urumchi, Xining, and Yinchuan, respectively. The lowest value of $9.1 \mathrm{~mm}$ was observed in 2009 at Urumchi; the lowest value of $9.3 \mathrm{~mm}$ was observed in 2008 at Xining; and the lowest value of $10.0 \mathrm{~mm}$ was observed in 2004 at Yinchuan.

For the stations in North China, a significant increasing trend in PWV was observed at Hohhot, Taiyuan, and Beijing from 1979 to 1998, with the largest PWV value occurring in 1997 for Beijing and in 1998 for Hohhot and Taiyuan (Figure 6(b)). In addition, a corresponding significant decrease was observed during 1997-2002 at Beijing 

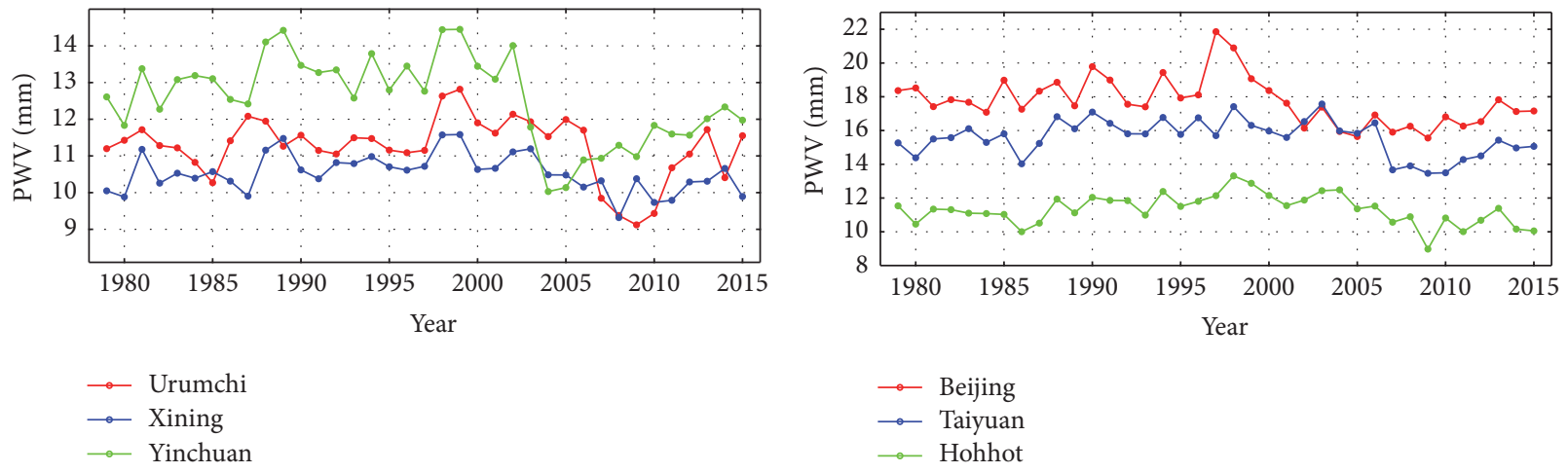

(a)

(b)

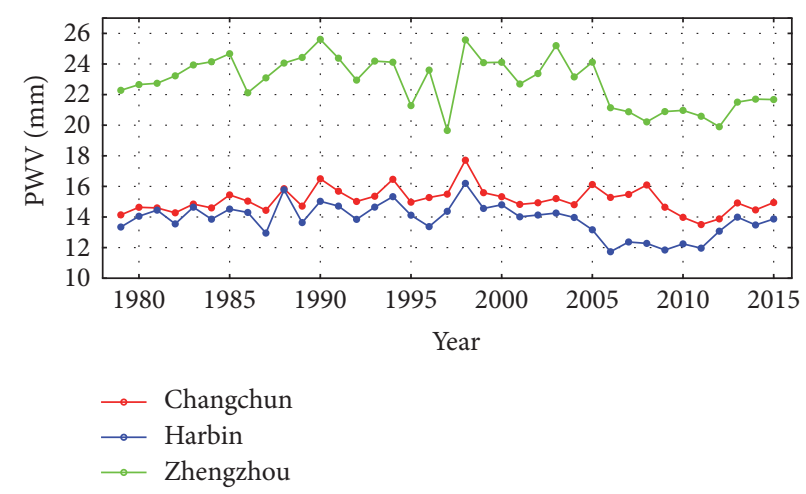

(c)

FIGURE 6: The annual averaged PWV time series derived from radiosonde observations throughout North China at the stations (a) Urumchi, Xining, and Yinchuan; (b) Beijing, Taiyuan, and Hohhot; and (c) Changchun, Harbin, and Zhengzhou.

and during 2003-2009 at Hohhot and Taiyuan. The largest PWV values were $21.9 \mathrm{~mm}, 17.4 \mathrm{~mm}$, and $13.3 \mathrm{~mm}$ for Beijing, Taiyuan, and Hohhot, respectively. The lowest PWV values were $15.6 \mathrm{~mm}, 13.5 \mathrm{~mm}$, and $9.0 \mathrm{~mm}$ for Beijing, Taiyuan, and Hohhot, respectively.

For the stations in Northeast China, a significant increasing trend in PWV was observed at Harbin and Changchun from 1979 to 1998 (Figure 6(c)). A corresponding significant decreasing trend was observed during 1998-2011 at Changchun and Harbin, followed by an increase during 2011-2015. For the Harbin station, the largest PWV value of $16.2 \mathrm{~mm}$ occurred in 1998, and the lowest PWV value of $11.7 \mathrm{~mm}$ occurred in 2006. For Changchun station, the largest PWV value of $17.7 \mathrm{~mm}$ occurred in 1998, and the lowest PWV value of $13.5 \mathrm{~mm}$ occurred in 2011.

\subsection{Trends in $P W V$ throughout North China}

3.2.1. Annual Trend in PWV throughout North China. The Fifth Assessment Report of the Intergovernmental Panel on Climate Change points out the explicitly human-induced warming trend of the climate system [50]. As a key climatic parameter, the long-term interannual variation and trend in PWV against the background of climate change are crucial for understanding global and regional climatic changes and the effect of the water vapor feedback on global warming. Linear regression trend analysis was performed for radiosonde,
ERA-interim, and MERRA-2 PWVs using the least-squares linear regression method. Figure 7 shows the spatial distributions of the linear trends for the three PWV datasets during three different periods (1979-1999, 1979-2007, and 2008-2015). As shown in Figures 7(a)-7(c), when the trend test was conducted over the period of 1979-1999, there was an increasing PWV trend at most stations in North China. Among the 45 sites, the number of sites displaying increasing trends from 1979 to 1999 was 44. Notably, the PWV trends derived from the ERA-interim and MERRA-2 reanalysis data were consistent with the radiosonde observations; an increasing trend was observed in North China during 1979-1999. The magnitude of the increasing trend ranged from $0.1 \mathrm{~mm}$ to $1.2 \mathrm{~mm}$ decade $^{-1}$ between 1979 and 1999. Stations with linear trends greater than $0.8 \mathrm{~mm}$ decade $^{-1}$ were in Northwestern China, North China, and Northeastern China.

In contrast, among the 45 sites in North China, the number of sites with increasing trend is 25 from 1979 to 2007, while the number of sites with decreasing trend is 20 (Figure $7(\mathrm{~d})$ ). These results indicate that the PWV in North China is not monotonically increasing under the context of global warming. In fact, some parts of North China experience a decreasing PWV in the recent decade. Unlike the PWV trend retrieved from radiosonde observations, the PWV trends of ERA-interim and MERRA-2 exhibited slightly different spatial distribution characteristics. The wide spatial ranges of the increasing trend were observed in ERA-interim 


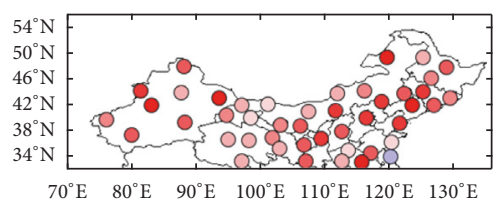

(a) Radiosonde: 1979-1999

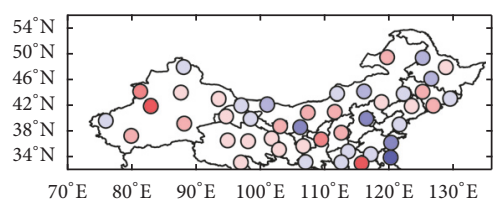

(d) Radiosonde: 1979-2007

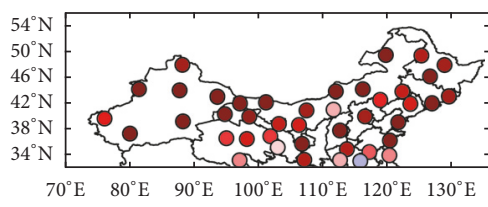

(g) Radiosonde: 2008-2015

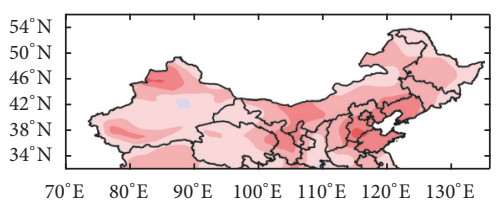

(b) ERA-interim: 1979-1999

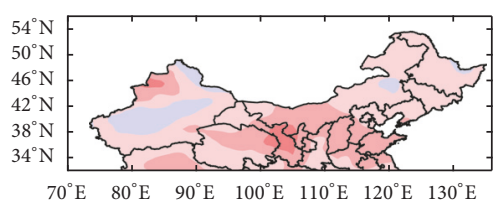

(e) ERA-interim: 1979-2007

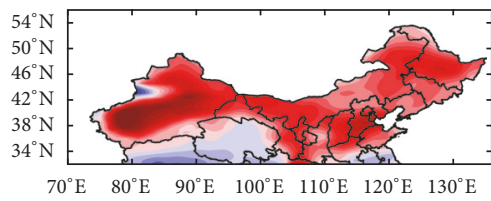

(h) ERA-interim: 2008-2015

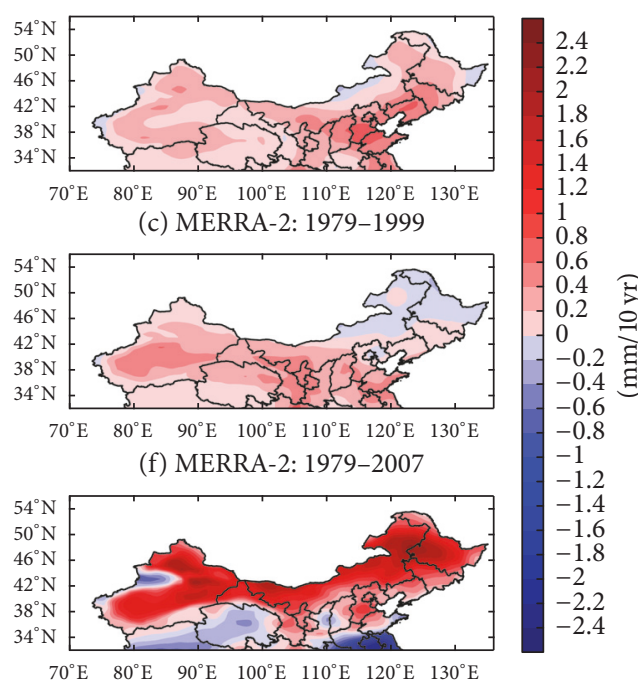

(i) MERRA-2: 2008-2015

FIGURE 7: Annual spatial distributions of linear trends from radiosonde, ERA-interim, and MERRA-2 PWVs for three periods: (a-c) 1979-1999, (d-f) 1979-2007, and (g-i) 2008-2015.

and MERRA-2. The high centers of increasing trends were mainly located in Mid-Eastern China and Southern Inner Mongolia, with the largest trend magnitude being $0.8 \mathrm{~mm}$ decade $^{-1}$. However, a slight decrease trend was found in Southern Xinjiang Province (for ERA-interim), Northern Heilongjiang Province, and Northern Inner Mongolia (for MERRA-2). For the period of 1979-2007, the higher PWV trends in ERA-interim and MERRA-2 when compared with radiosonde PWV are attributed to the effects of PWV overestimation before 1992 (Chen et al., 2016).

When the linear trend test was performed over the period of 2008-2015, almost all radiosonde sites displayed increasing trends. Stations with increasing trend magnitude greater than $2.4 \mathrm{~mm}_{\text {decade }}^{-1}$ were located in Xinjiang Province, Northern Inner Mongolia, and Northern Heilongjiang Province. What is more, similar positive PWV trends with magnitudes ranging from $0.8 \mathrm{~mm}$ to $2.2 \mathrm{~mm}$ decade $^{-1}$, retrieved from ERA-interim and MERRA-2 data, were observed throughout most regions of North China, except for Northern Tibetan Plateau, Qinghai Province, and Mid-Eastern China (Figures 7(h)-7(i)). However, it should be noted the above trends need to be confirmed in the future because the Chinese radiosonde data during 2008-2015 contain the inhomogeneity. There are known severe inhomogeneities in Chinese radiosonde records after 2007, particularly at higher altitudes. As for the trends from reanalyses, which assimilate the radiosonde record data, they could also be biased due to the inhomogeneity of the radiosonde moisture data.

3.2.2. Seasonal Trends in PWV throughout North China. The seasonal (spring: March-May; summer: June-August; autumn: September-November; and winter: December-February) PWV trends derived from 45 collocated radiosonde stations during three periods (1979-1999, 1979-2007, and 2008-2015) are presented in Figure 8. As shown in Figures $8(\mathrm{a}), 8(\mathrm{~d}), 8(\mathrm{~g})$, and $8(\mathrm{j})$, when the linear trend test was conducted over the period of 1979-1999, 44, 44, 39, and 43 of 45 sites displayed increasing trends in all four seasons. These results indicate that a clear increasing PWV trend occurred at most sites in North China in all four seasons from 1979 to 1999, with the maximum average increase occurring in summer and the minimum occurring in winter. Meanwhile, among the 45 stations, the numbers of stations with decreasing trend during 1979-2007 are 26, 15, 18, and 19 in spring, summer, autumn, and winter, respectively (Figures $8(\mathrm{~b}), 8(\mathrm{e}), 8(\mathrm{~h})$, and $8(\mathrm{k}))$. In spring, the PWV trend in Mid-Eastern China showed relatively significant decreasing trends, ranging from -0.8 to $-0.2 \mathrm{~mm} \mathrm{decade} \mathrm{e}^{-1}$. In summer, the decreasing trend in Central China was reversed, but a weaker decreasing trend occurred in eastern margin of China. In autumn, a similar trend distribution pattern compared with that in summer was observed throughout most regions of North China. The spatial distribution of the PWV trends in winter between 1979 and 2007 is similar to summer and autumn, with slight increases occurring in Xinjiang and Liaoning Province and slight decreases occurring in Inner Mongolia. In contrast, an increasing trend is pronounced in four seasons throughout North China between 2008 and 2015. The number of sites with an increasing trend from 2008 to 2015 was $41,40,35$, and 42 in spring, summer, autumn, and winter, respectively. Overall, an increasing trend was observed at most stations of North China in spring. The maximum magnitude of an increasing trend occurred throughout Mid-Eastern China and Xinjiang Province and was about $2 \mathrm{~mm}$ decade ${ }^{-1}$. In summer, a relatively larger increasing trend was observed at most sites in North China, Xinjiang, and Qinghai Province, but a significant decreasing trend occurred in Mid-Eastern China with the trends being about $-2 \mathrm{~mm}$ decade $^{-1}$. In autumn, the spatial distribution of the PWV trends was similar to the PWV trends in 


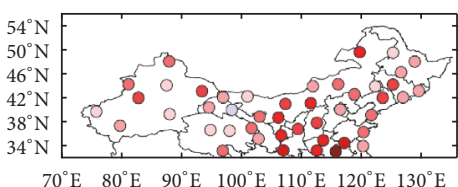

(a) Spring: 1979-1999

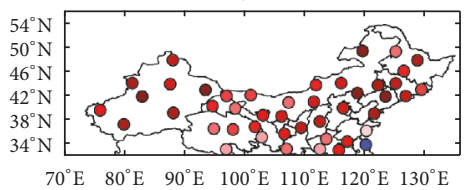

(d) Summer: 1979-1999

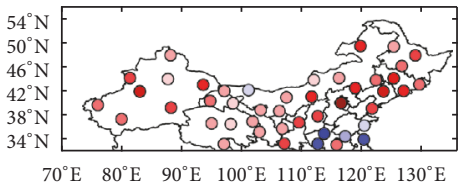

(g) Autumn: 1979-1999

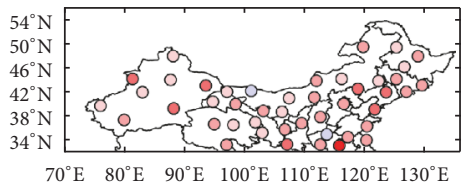

(j) Winter: 1979-1999

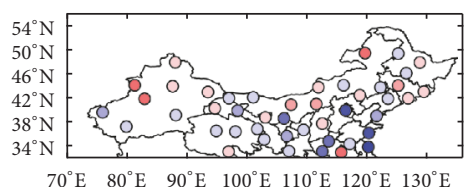

(b) Spring: 1979-2007

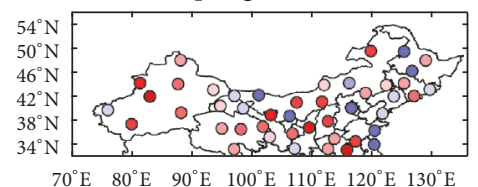

(e) Summer: 1979-2007

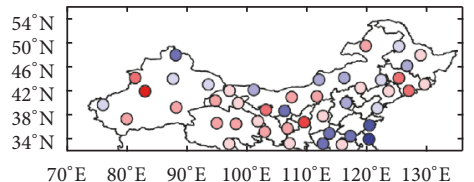

(h) Autumn: 1979-2007

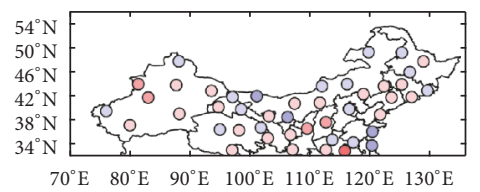

(k) Winter: 1979-2007

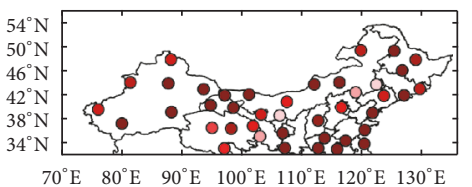

(c) Spring: 2008-2015

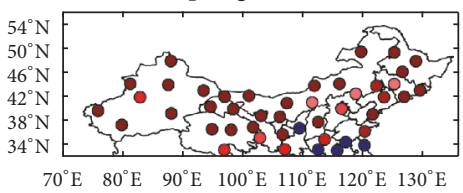

(f) Summer: 2008-2015

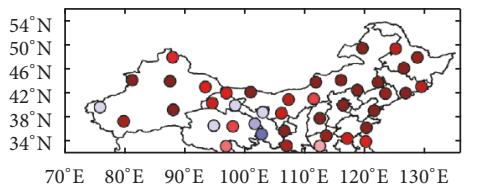

(i) Autumn: 2008-2015

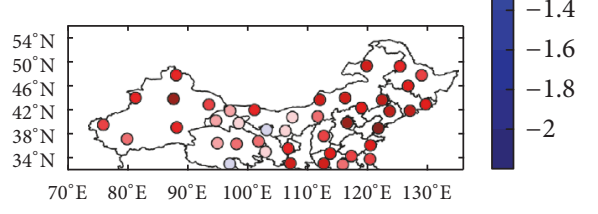

(l) Winter: 2008-2015

FIGURE 8: Seasonal spatial distributions of linear trends from the radiosonde PWV for three periods: (a, d, g, j) 1979-1999, (b, e, h, k) 1979-2007, and (c, f, i, l) 2008-2015.

spring. In winter, almost all sites in North China showed a relatively slight increasing trend when compared with the other seasons, but the magnitude of the increasing trend ranged from 0.2 to $2 \mathrm{~mm} \mathrm{decade}^{-1}$ between 2008 and 2015 . However, the above seasonal trends during 2008-2015 also need deeper analysis to be confirmed in the future due to the Chinese radiosonde data inhomogeneities.

\section{Conclusion}

This study reveals the distributions of annual, seasonal, and monthly mean PWV, as well as the interannual variations and trends in PWV, throughout North China, based on three PWV datasets, radiosonde observations and and ECMWF and MERRA-2 reanalysis data, from 1979 to 2015. The distribution of PWV throughout North China showed clear geographical differences. This spatial pattern of annual mean PWV throughout North China was generally characterized by two high PWV centers, located in Eastern China (ranging from 20 to $28 \mathrm{~mm}$ ) and in the Tarim Basin (about $12 \mathrm{~mm}$ ), and two low PWV centers, located in Northern Tibet and Qinghai Province (ranging from 2 to $8 \mathrm{~mm}$ ) and in the highlatitude Inner Mongolia region (about $8 \mathrm{~mm}$ ). Affected by the East Asian monsoon, the levels of seasonal mean PWV were highest in summer, followed by autumn and spring, and were lowest in winter. Based on the monthly mean PWV, the highest PWV level in North China occurred in July and August, which was closely related to the enhanced intensity of the East Asian summer monsoon and increased evaporation resulting from increased temperatures during this period. The lowest PWV level in North China occurred in December, January, and February.

The trends in the interannual variations of averaged time series of annual mean PWV in ERA-interim and MERRA2 reanalysis data were highly consistent with the observed radiosonde PWV series in North China. The largest PWV value occurred in 1998 and the lowest PWV value occurred in 2009. Increasing trends in annual mean PWV, with the trend magnitude ranging from $0.1 \mathrm{~mm}$ to $1.2 \mathrm{~mm}$ decade $^{-1}$ in North China, were found in the radiosonde, ERA-interim, and MERRA-2 data from 1979 to 1999 , using the least-squares linear regression method. For the period of 1979-2007, slightly decreased trends of $-0.4 \mathrm{~mm}^{\text {decade }}{ }^{-1}$ are observed in most regions of North China. For the recent 8 years, 2008-2015, although all the PWV datasets show upward trends in North China with the largest value of $2.4 \mathrm{~mm}$ decade $^{-1}$ from the radiosonde, the data homogeneity must be checked in the future.

Based on data from 37 radiosonde stations, clear increasing PWV trends were found at most sites in North China in all four seasons from 1979 to 1999 , with the maximum average increase occurring in summer and the minimum occurring in winter. A slightly but less marked decrease trend was found at most stations in North China in all four seasons during 1979-2007. In addition to the apparent increasing trend of PWV during 1979-1999, the increased trends (with the maximum in summer) were also found throughout North China during the period from 2008 to 2015; however, these 
trends need to be confirmed after resolving the radiosonde data inhomogeneities over North China region in the future.

\section{Conflicts of Interest}

The authors declare that there are no conflicts of interest regarding the publication of this paper.

\section{Acknowledgments}

This work is financially supported by National Key R\&D Program of China (2016YFA0601901), National Natural Science Foundation of China (41590874 and 41375153), project of National Special Environment and Function Observation Research Sharing Service Infrastructure, and Young Talent Project of Heilongjiang Meteorological Administration (2015YT002).

\section{References}

[1] I. M. Held and B. J. Soden, "Water vapor feedback and global warming," Annual Review of Environment and Resources, vol. 25, pp. 441-475, 2000.

[2] K. E. Trenberth, J. Fasullo, and L. Smith, "Trends and variability in column-integrated atmospheric water vapor," Climate Dynamics, vol. 24, no. 7-8, pp. 741-758, 2005.

[3] J. Wang, D. J. Carlson, D. B. Parsons et al., "Performance of operational radiosonde humidity sensors in direct comparison with a chilled mirror dew-point hygrometer and its climate implication," Geophysical Research Letters, vol. 30, no. 16, 2003.

[4] T. Wagner, S. Beirle, M. Grzegorski, and U. Platt, "Global trends (1996-2003) of total column precipitable water observed by Global Ozone Monitoring Experiment (GOME) on ERS2 and their relation to near-surface temperature," Journal of Geophysical Research: Atmospheres, vol. 111, no. 12, Article ID D12102, 2006.

[5] A. Dai, "Recent climatology, variability, and trends in global surface humidity," Journal of Climate, vol. 19, no. 15, pp. 35893606, 2006.

[6] A. Dai, J. Wang, P. W. Thorne, D. E. Parker, L. Haimberger, and X. L. Wang, "A new approach to homogenize daily radiosonde humidity data," Journal of Climate, vol. 24, no. 4, pp. 965-991, 2011.

[7] T. Zhao, A. Dai, and J. Wang, "Trends in tropospheric humidity from 1970 to 2008 over china from a homogenized radiosonde dataset," Journal of Climate, vol. 25, no. 13, pp. 4549-4567, 2012.

[8] S. Mieruch, S. Noël, H. Bovensmann, and J. P. Burrows, "Analysis of global water vapour trends from satellite measurements in the visible spectral range," Atmospheric Chemistry and Physics, vol. 8, no. 3, pp. 491-504, 2008.

[9] L. Zhang, L. Wu, and B. Gan, "Modes and mechanisms of global water vapor variability over the twentieth century," Journal of Climate, vol. 26, no. 15, pp. 5578-5593, 2013.

[10] G. Elgered, J. M. Johansson, B. O. Rönnäng, and J. L. Davis, "Measuring regional atmospheric water vapor using the Swedish permanent GPS network," Geophysical Research Letters, vol. 24, no. 21, pp. 2663-2666, 1997.

[11] I. Durre, R. S. Vose, and D. B. Wuertz, "Overview of the integrated global radiosonde archive," Journal of Climate, vol. 19, no. 1, pp. 53-68, 2006.
[12] J. L. Sánchez, R. Posada, E. García-Ortega, L. López, and J. L. Marcos, "A method to improve the accuracy of continuous measuring of vertical profiles of temperature and water vapor density by means of a ground-based microwave radiometer," Atmospheric Research, vol. 122, pp. 43-54, 2013.

[13] G. Xu, R. S. Ware, W. Zhang, G. Feng, K. Liao, and Y. Liu, "Effect of off-zenith observations on reducing the impact of precipitation on ground-based microwave radiometer measurement accuracy," Atmospheric Research, vol. 140-141, pp. 85-94, 2014.

[14] D. N. Whiteman, M. Cadirola, D. Venable et al., "Correction technique for Raman water vapor lidar signal-dependent bias and suitability for water vapor trend monitoring in the upper troposphere," Atmospheric Measurement Techniques, vol. 5, no. 11, pp. 2893-2916, 2012.

[15] X. Li, L. Zhang, X. Cao et al., "Retrieval of precipitable water vapor using MFRSR and comparison with other multisensors over the semi-arid area of northwest China," Atmospheric Research, vol. 172-173, pp. 83-94, 2016.

[16] B. Gao and Y. J. Kaufman, "Water vapor retrievals using moderate resolution imaging spectroradiometer (MODIS) nearinfrared channels," Journal of Geophysical Research: Atmospheres, vol. 108, no. D13, 2003.

[17] R. R. Nelson, D. Crisp, L. E. Ott, and C. W. O'Dell, "Highaccuracy measurements of total column water vapor from the Orbiting Carbon Observatory-2," Geophysical Research Letters, vol. 43, no. 23, pp. 12-269, 2016.

[18] M. D. Alexandrov, B. Schmid, D. D. Turner et al., "Columnar water vapor retrievals from multifilter rotating shadowband radiometer data," Journal of Geophysical Research: Atmospheres, vol. 114, no. 2, Article ID D02306, 2009.

[19] H. Che, K. Gui, Q. Chen et al., "Calibration of the $936 \mathrm{~nm}$ watervapor channel for the China aerosol remote sensing NETwork (CARSNET) and the effect of the retrieval water-vapor on aerosol optical property over Beijing, China," Atmospheric Pollution Research, vol. 7, no. 5, pp. 743-753, 2016.

[20] M. J. Brettle and J. F. Galvin, "Back to basics: radiosondes: part 1-the instrument," Weather, vol. 58, no. 9, pp. 336-341, 2003.

[21] B. Adeyemi and S. Joerg, "Analysis of water vapor over Nigeria using radiosonde and satellite data," Journal of Applied Meteorology and Climatology, vol. 51, no. 10, pp. 1855-1866, 2012.

[22] Z. Liu, M. S. Wong, J. Nichol, and P. W. Chan, "A multisensor study of water vapour from radiosonde, MODIS and AERONET: A case study of Hong Kong," International Journal of Climatology, vol. 33, no. 1, pp. 109-120, 2013.

[23] D. P. Dee, S. M. Uppala, A. J. Simmons et al., “The ERA-Interim reanalysis: configuration and performance of the data assimilation system," Quarterly Journal of the Royal Meteorological Society, vol. 137, no. 656, pp. 553-597, 2011.

[24] D. R. Easterling and T. C. Peterson, "A new method for detecting undocumented discontinuities in climatological time series," International Journal of Climatology, vol. 15, no. 4, pp. 369-377, 1995.

[25] A. E. Dessler and S. M. Davis, "Trends in tropospheric humidity from reanalysis systems," Journal of Geophysical Research: Atmospheres, vol. 115, no. D19, 2010.

[26] R. P. Allan, A. Slingo, and V. Ramaswamy, "Analysis of moisture variability in the European Centre for Medium-Range Weather Forecasts 15-year reanalysis over the tropical oceans," Journal of Geophysical Research: Atmospheres, vol. 107, no. D15, 2002. 
[27] N. Lu, J. Qin, Y. Gao et al., "Trends and variability in atmospheric precipitable water over the Tibetan Plateau for 20002010," International Journal of Climatology, vol. 35, no. 7, pp. 1394-1404, 2015.

[28] E. K. Oikonomou and A. O’Neill, "Evaluation of ozone and water vapor fields from the ECMWF reanalysis ERA-40 during 1991-1999 in comparison with UARS satellite and MOZAIC aircraft observations," Journal of Geophysical Research: Atmospheres, vol. 111, no. 14, Article ID D14109, 2006.

[29] S. C. Sherwood, R. Roca, T. M. Weckwerth, and N. G. Andronova, "Tropospheric water vapor, convection, and climate," Reviews of Geophysics, vol. 48, no. 2, Article ID RG2001, 2010.

[30] R. J. Ross and W. P. Elliot, "Radiosonde-based Northern Hemisphere tropospheric water vapor trends," Journal of Climate, vol. 14, no. 7, pp. 1602-1612, 2001.

[31] B. Xie, Q. Zhang, and Y. Ying, "Trends in precipitable water and relative humidity in China: 1979-2005," Journal of Applied Meteorology and Climatology, vol. 50, no. 10, pp. 1985-1994, 2011.

[32] L. Bengtsson, S. Hagemann, and K. I. Hodges, "Can climate trends be calculated from reanalysis data?" Journal of Geophysical Research: Atmospheres, vol. 109, no. 11, Article ID D11111, 2004.

[33] A. Takahashi, T. Hiyama, M. Nishikawa et al., "Diurnal variation of water vapor mixing between the atmospheric boundary layer and free atmosphere over Changwu, the Loess Plateau in China," Scientific Online Letters on the Atmosphere, vol. 4, no. 1, pp. 33-36, 2008.

[34] M. Schröder, M. Jonas, R. Lindau, J. Schulz, and K. Fennig, "The CM SAF SSM/I-based total column water vapour climate data record: methods and evaluation against reanalyses and satellite," Atmospheric Measurement Techniques, vol. 6, no. 3, pp. 765-775, 2013.

[35] B. Chen and Z. Liu, "Global water vapor variability and trend from the latest 36 year (1979 to 2014) data of ECMWF and NCEP reanalyses, radiosonde, GPS, and microwave satellite," Journal of Geophysical Research: Atmospheres, vol. 121, no. 19, pp. 11442$11462,2016$.

[36] B. Chen and Z. Liu, "A Comprehensive Evaluation and Analysis of the Performance of Multiple Tropospheric Models in China Region," IEEE Transactions on Geoscience and Remote Sensing, vol. 54, no. 2, pp. 663-678, 2016.

[37] D. D. Turner, B. M. Lesht, S. A. Clough, J. C. Liljegren, H. E. Revercomb, and D. C. Tobin, "Dry bias and variability in Vaisala RS80-H radiosondes: The ARM experience," Journal of Atmospheric and Oceanic Technology, vol. 20, no. 1, pp. 117-132, 2003.

[38] D. Pérez-Ramírez, D. N. Whiteman, A. Smirnov et al., "Evaluation of AERONET precipitable water vapor versus microwave radiometry, GPS, and radiosondes at ARM sites," Journal of Geophysical Research: Atmospheres, vol. 119, no. 15, pp. 95969613, 2014.

[39] M. S. Wong, X. Jin, Z. Liu, J. Nichol, and P. W. Chan, "Multisensors study of precipitable water vapour over mainland China," International Journal of Climatology, vol. 35, no. 10, pp. 3146-3159, 2015.

[40] K. Gui, H. Che, Q. Chen et al., "Water vapor variation and the effect of aerosols in China," Atmospheric Environment, vol. 165, pp. 322-335, 2017.

[41] S. Chandra, J. R. Ziemke, W. Min, and W. G. Read, "Effects of 1997-1998 El Niño on tropospheric ozone and water vapor,"
Geophysical Research Letters, vol. 25, no. 20, pp. 3867-3870, 1998.

[42] R. Lindstrot, M. Stengel, M. Schröder et al., "A global climatology of total columnar water vapour from SSM/I and MERIS," Earth System Science Data, vol. 6, no. 1, pp. 221-233, 2014.

[43] Y. Wang, K. Yang, Z. Pan et al., "Evaluation of precipitable water vapor from four satellite products and four reanalysis datasets against gps measurements on the southern tibetan plateau," Journal of Climate, vol. 30, no. 15, pp. 5699-5713, 2017.

[44] M. Schröder, M. Lockhoff, J. M. Forsythe, H. Q. Cronk, T. H. Vonder Haar, and R. Bennartz, "The GEWEX water vapor assessment: results from intercomparison, trend, and homogeneity analysis of total column water vapor," Journal of Applied Meteorology and Climatology, vol. 55, no. 7, pp. 1633-1649, 2016.

[45] A. M. Moussa, B. Diop, A. Diakhaby, A. Deme, and A. Sy, "Precipitable water vapor, temperature and humidity retrieval using AMSU-A, MHS and HIRS," International Journal of Innovation and Applied Studies, vol. 9, p. 1793, 2014.

[46] M. M. Rienecker, M. J. Suarez, R. Gelaro et al., "MERRA: NASA's modern-era retrospective analysis for research and applications," Journal of Climate, vol. 24, no. 14, pp. 3624-3648, 2011.

[47] J. Roman, R. Knuteson, T. August, T. Hultberg, S. Ackerman, and H. Revercomb, "A global assessment of NASA AIRS v6 and EUMETSAT IASI v6 precipitable water vapor using groundbased GPS SuomiNet stations," Journal of Geophysical Research: Atmospheres, vol. 121, no. 15, pp. 8925-8948, 2016.

[48] T. Zhao, J. Wang, and A. Dai, "Evaluation of atmospheric precipitable water from reanalysis products using homogenized radiosonde observations over China," Journal of Geophysical Research: Atmospheres, p. 120, 2015.

[49] X. Dai, W. Li, Z. Ma, and P. Wang, "Water-vapor source shift of Xinjiang region during the recent twenty years," Progress in Natural Science, vol. 17, no. 5, pp. 569-575, 2007.

[50] Intergovernmental Panel on Climate Change, Climate Change 2013-The Physical Science Basis. Contribution of Working Group I to the Fifth Assessment Report of the Intergovernmental Panel on Climate Change, T. F. Stocker, D. Qin, G.-K. Plattner, Eds., Cambridge University Press, Cambridge, UK, 2013. 

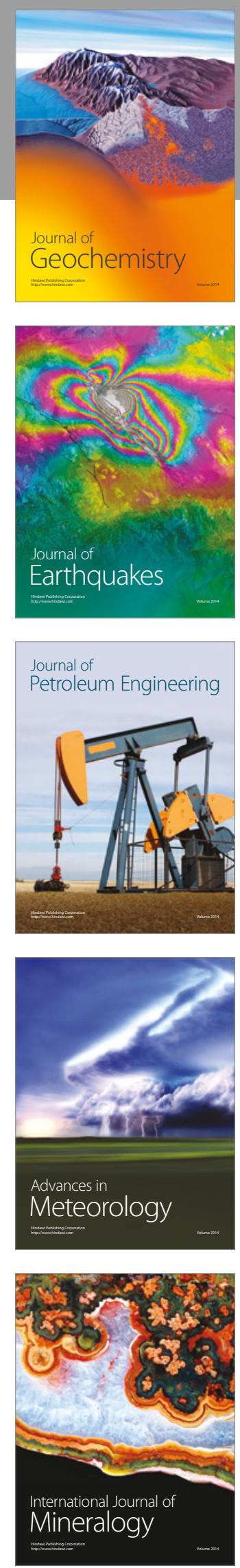
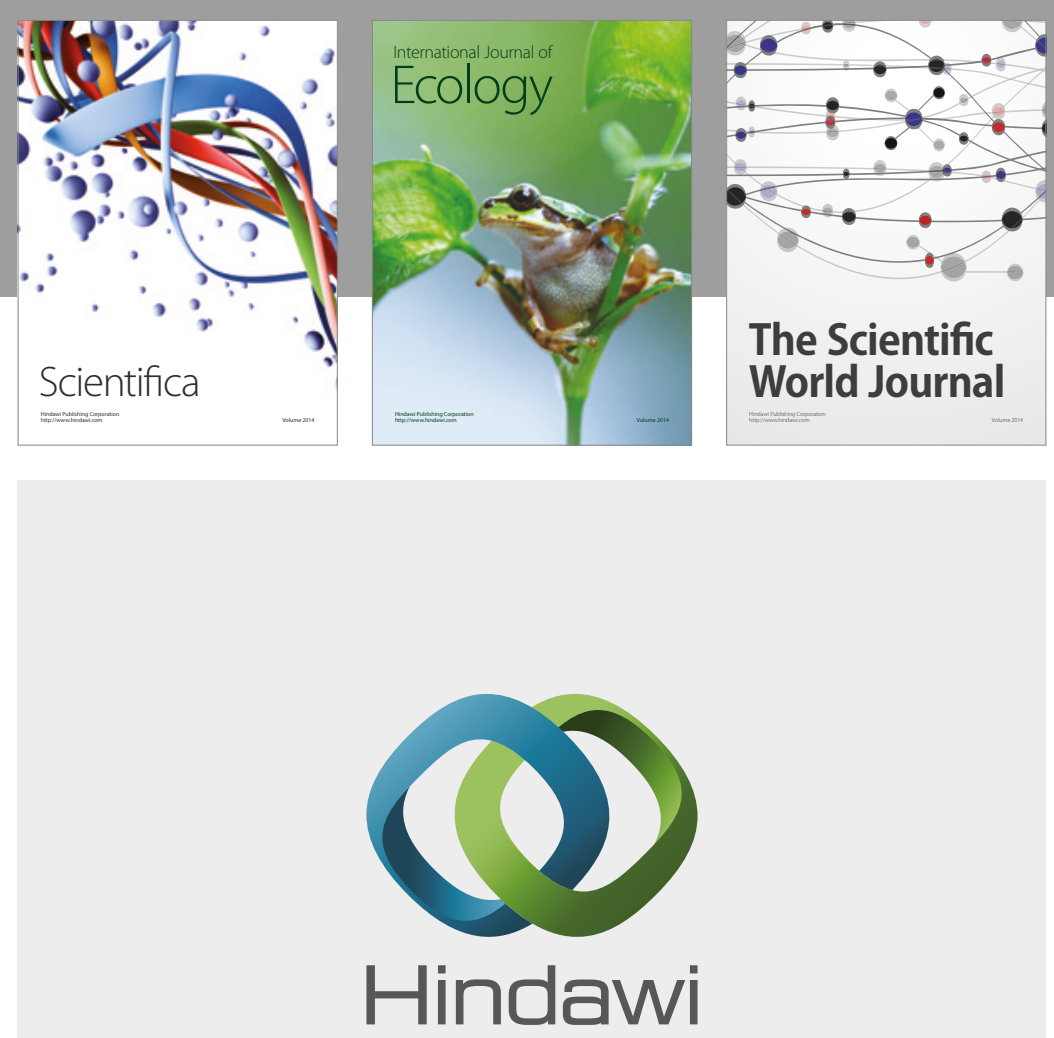

Submit your manuscripts at

https://www.hindawi.com
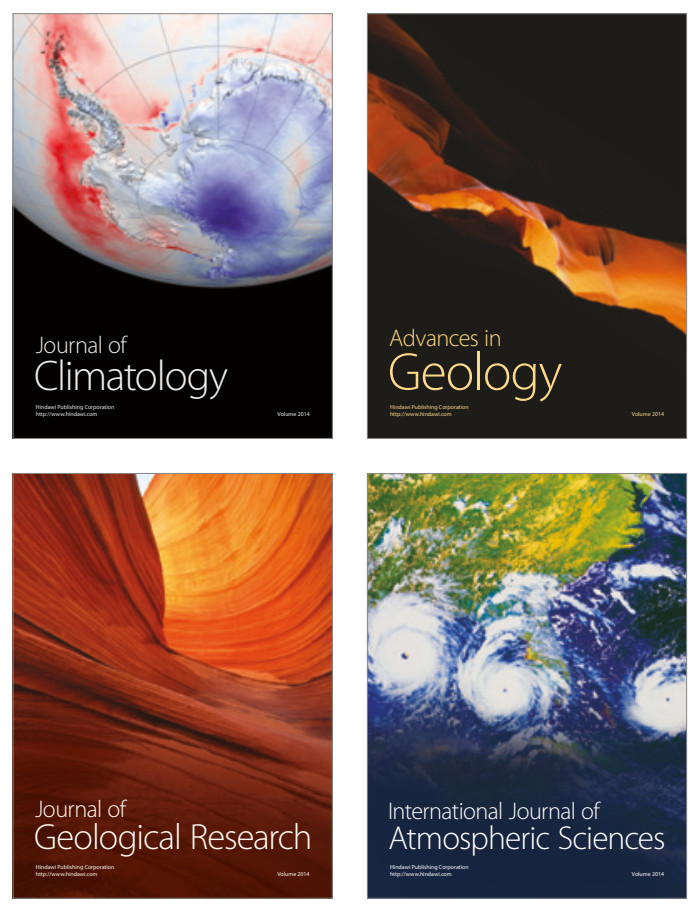

The Scientific

World Journal
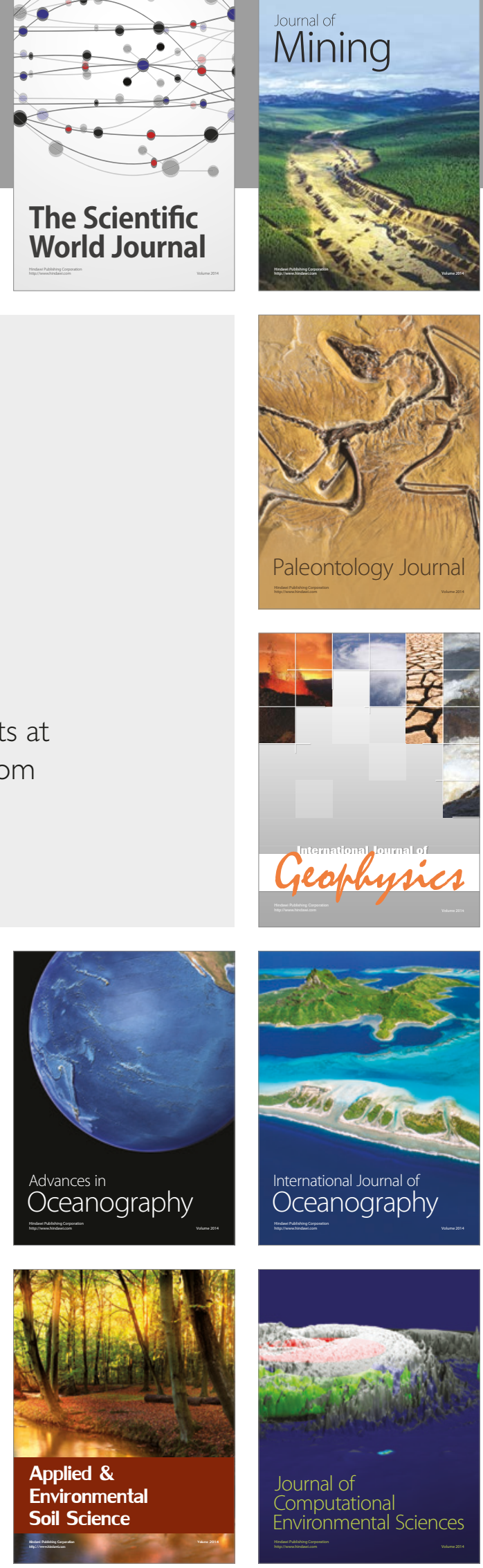